OPEN ACCESS

Edited by:

Gianrico Spagnuolo, University of Naples Federico II, Italy

Reviewed by: Andrei Cristian lonescu, University of Milan, Italy Rossana Izzetti,

University of Pisa, Italy

*Correspondence: Yiu Yan Leung

mikeyyleung@hku.hk

Specialty section:

This article was submitted to

Dental Materials,

a section of the journa

Frontiers in Dental Medicine

Received: 18 June 2021 Accepted: 06 October 2021 Published: 05 November 2021

Citation:

Tsoi JKH, Ding H, Hon K and Leung YY (2021) The Spread of Droplets and Aerosols of Surgical Motor Handpiece Irrigation Using

Different Suction Systems.

Front. Dent. Med. 2:727111. doi: 10.3389/fdmed.2021.727111

\section{The Spread of Droplets and Aerosols of Surgical Motor Handpiece Irrigation Using Different Suction Systems}

\author{
James K. H. Tsoi ${ }^{1}$, Hao Ding ${ }^{1}$, Ki Hon ${ }^{2}$ and Yiu Yan Leung ${ }^{3 *}$ \\ ${ }^{1}$ Applied Oral Sciences \& Community Dental Care, Faculty of Dentistry, The University of Hong Kong, Pokfulam, Hong Kong \\ SAR, China, ${ }^{2}$ Restorative Dental Sciences, Faculty of Dentistry, The University of Hong Kong, Pokfulam, Hong Kong SAR, \\ China, ${ }^{3}$ Oral and Maxillofacial Surgery, Faculty of Dentistry, The University of Hong Kong, Pokfulam, Hong Kong SAR, China
}

Objective: This study aimed to compare the effectiveness of various combinations of dental suction devices in reducing the amount and distance of spread of aerosols and droplets using an electrical surgical motor model with a self-irrigation system.

Materials and Methods: In a standard single-chaired air-conditioned ventilated dental clinic, an electrical dental surgical motor with a high-speed handpiece (Implantmed) cooled with $0.2 \%$ fluorescein containing normal saline was used to drill a gypsum block mounted on a phantom head in a supine position. A single operator performed thrice each of the following suction settings: (a) no suction, (b) low-volume suction, (c) low-volume + high-volume suctions, and (d) low-volume + external oral suctions. Aerosols $(0.1-5 \mu \mathrm{m})$ were measured with a particle counter at the mouth opening of the phantom head, and droplet sizes and distances were analyzed via a machine learning algorithm by identifying fluorescence droplets on pre-loaded pieces of paper on the floor for each group.

Results: The different suction systems have different performances in terms of droplet distance $(p=0.007)$, whereas using (c) high volume suctions $(41.1 \pm 22.9 \mathrm{~cm})$ and (d) external oral suction unit (39 $\pm 18.2 \mathrm{~cm}$ ) had significantly reduced the spread of droplets when compared with (a) without suction $(58.9 \pm 17.1 \mathrm{~cm})$. Using (d) external oral suction or (c) high volume suction could reduce the number for all droplet sizes. The use of (c) high volume suction was most effective in reducing aerosol count of 0.3-1 $\mu \mathrm{m}$, while (d) external oral suction was most effective in reducing aerosol count of 3-5 $\mu \mathrm{m}$.

Conclusions: Both external oral suction and high-volume suction were effective in reducing aerosols and droplets generated by the irrigation of a surgical high-speed motor handpiece. External oral suction could be an effective alternative to high volume suction in dental surgical procedures to reduce the spread of aerosols and droplets.

Clinical Relevance: External oral suction or high-volume suction should be used in conjunction with low-volume suction in surgical procedure to reduce the spread of aerosols and droplets in a dental clinic environment.

Keywords: aerosol, droplet, extra-oral suction, COVID-19, irrigation 


\section{INTRODUCTION}

Multiple viruses, such as coronavirus, can be transmitted via aerosols and droplets $(1,2)$. Rotary and ultrasonic instruments, which generate a large amount of droplets and aerosols, are used in dental procedures on a daily basis. These particles can spread over a distance and contaminate the surrounding environment. The source of aerosols and droplets come from water as a coolant of instruments. In principle, a particles size of $<5 \mu \mathrm{m}$ is regarded as aerosols or droplet nuclei, and those $5-500 \mu \mathrm{m}$ are defined as droplets $(3,4)$. Former studies (5, 6) on dental bioaerosols (i.e., aerosols loaded with biological substances) from the 1960s to 2018 have only addressed bacterial transmission but not viruses. Viruses, having a much smaller size and lower weight than bacteria, may spread more easily with aerosols and droplets. Dental clinics may, therefore, potentiate the transmission of virus particles especially in times of pandemic like the coronavirus disease-2019 (COVID-19). Facemasks with high filtering function were proven to reduce the transmission and viral load of infectious droplets and aerosols (7). High filtering capacity facemasks, such as respirator masks and surgical masks, are designed to filter over $90 \%$ of virus-size pollutants, and offer the best feasible protection in a dental clinic setting (8). A number of measures were also suggested by dental professional bodies to reduce aerosols, such as hand scaling instead of ultrasonic scaling and the use of rubber dams in restorative work (9). However, these measures may not be feasible in some aerosol/droplet-generating dental procedures, such as surgical removal of third molars, with a large amount of viral particles generated and spread to a certain distance within the dental clinic during the procedure. With the fact that asymptomatic "silent carriers" of severe acute respiratory syndrome coronavirus-2 (SARS-CoV2 virus) are present in the community, there is a possibility of retained viral particles in the dental clinic that could infect other patients and the dental team, despite the use of sufficient personal protective equipment (PPE).

Different suction systems play an important role in reducing aerosol and droplet production during dental procedures. These devices are implemented for removal of saliva or liquids (water from devices or blood) during dental procedures to provide a clearer operation field for visibility and for the comfort of patients (10). A suction device has a suction tip connected to a vacuum container that can generate a negative pressure on a separator plumbing tank. The air and fluids from the operatory are sucked into the tank by the Venturi effect. Low-volume suction and high-volume suction are differentiated by their negative air flow. Low-volume suctions are usually portable units and could be easily adapted in different settings or could provide additional suction when required, which is useful especially in oral surgical procedures. High volume suctions are connected to a dental chair system as a fixed unit and could provide strong suction for routine dental procedures. Studies have shown that a properly positioned suction can remove dental aerosols with a highvolume setting (11) but ineffective with a low-volume setting (10). External oral suction units that claim to be capable of reducing dental aerosols are recently promoted in the market since the start of the COVID-19 pandemic. An external oral suction unit is a stand-alone suction machine that is placed near an operating field, which could spare a dental assistant from holding the tip of the suction. It also contains a fan coil unit and a high-efficiency particulate air (HEPA) filter that can decontaminate and filter suctioned air. Despite reports that show that portable HEPA devices could prevent $\sim 98 \%$ of aerosols in a temporary anteroom setup, professional bodies have criticized that there is no evidence that these external oral suction units are effective in reducing aerosols/droplets in dental clinics (12). In the era of the pandemic that is expected to last until an effective vaccine is developed, it is important to know which suction units or their combinations could be most effective in reducing the amount of aerosols and droplets, and in reducing the distance of their spread, in particular, in procedures that other preventive measures, such as rubber dam isolation, could not be implemented.

The aim of the study was to compare the effectiveness of various dental suction device combinations in reducing the amount and distance of spread of aerosols and droplets from an electrical surgical motor model with a self-irrigation system.

\section{MATERIALS AND METHODS}

\section{Experimental Setup}

This experiment was operated in a single chaired clinic with a size of $\sim 6 \mathrm{~m}(\mathrm{~L}) \times 4.4 \mathrm{~m}(\mathrm{~W}) \times 3 \mathrm{~m}(\mathrm{H})$ in a fully $\mathrm{A} / \mathrm{C}$ ventilated dental hospital (Figure 1). A training phantom head was secured on the chair with a gypsum cast mounted in the oral cavity. An electrical dental-surgical motor with a high speed handpiece (Implantmed, W\&H, Austria) was used. For the coolant and indicator of droplets, $0.2 \%(\mathrm{w} / \mathrm{v})$ fluorescein $(\mathrm{BDH}$ Chemicals, Poole, United Kingdom) in 0.9\% normal saline (Lot: 9B711; Otsuka Pharmaceutical, Thailand) was freshly prepared, and 80gsm $\left(\mathrm{g} / \mathrm{m}^{2}\right)$ pieces of paper were laid to cover the floor. The average air changes per hour was 10.5 in the clinic (at temperature $\left(20.6^{\circ} \mathrm{C}+/-2^{\circ} \mathrm{C}\right.$, relative humidity $\left.52.6 \%\right)$. No human subjects were involved in this experiment.

\section{Operative Procedure}

A single operator in normal clinical standard precautionary protective equipment (PPE), i.e., surgical mask (Medicom, Canada), gown (Medicom, Canada), headcap, and mist-free face shield (Contour Shield, Hong Kong), performed the drilling at $40,000 \mathrm{rpm}$ for $15 \mathrm{~s}$ on a gypsum block mounted on a phantom head secured on a dental chair headrest in the supine position. The following settings were tested: (a) no suction, (b) low-volume suction (Compact High Suction Pump; Clements Medical Equipment, Australia), (c) low-volume suction + highvolume vacuum suction from hospital, and (d) surgical suction + external oral suction unit (COXO, People's Republic of China). For low-volume and high-volume vacuum suctions, the suction tips were held by a PPE-dressed employee with dental assistance training, and suctioned in normal position. For the external oral suction unit, the air inlet was placed $\sim 5 \mathrm{~cm}$ from the oral cavity 


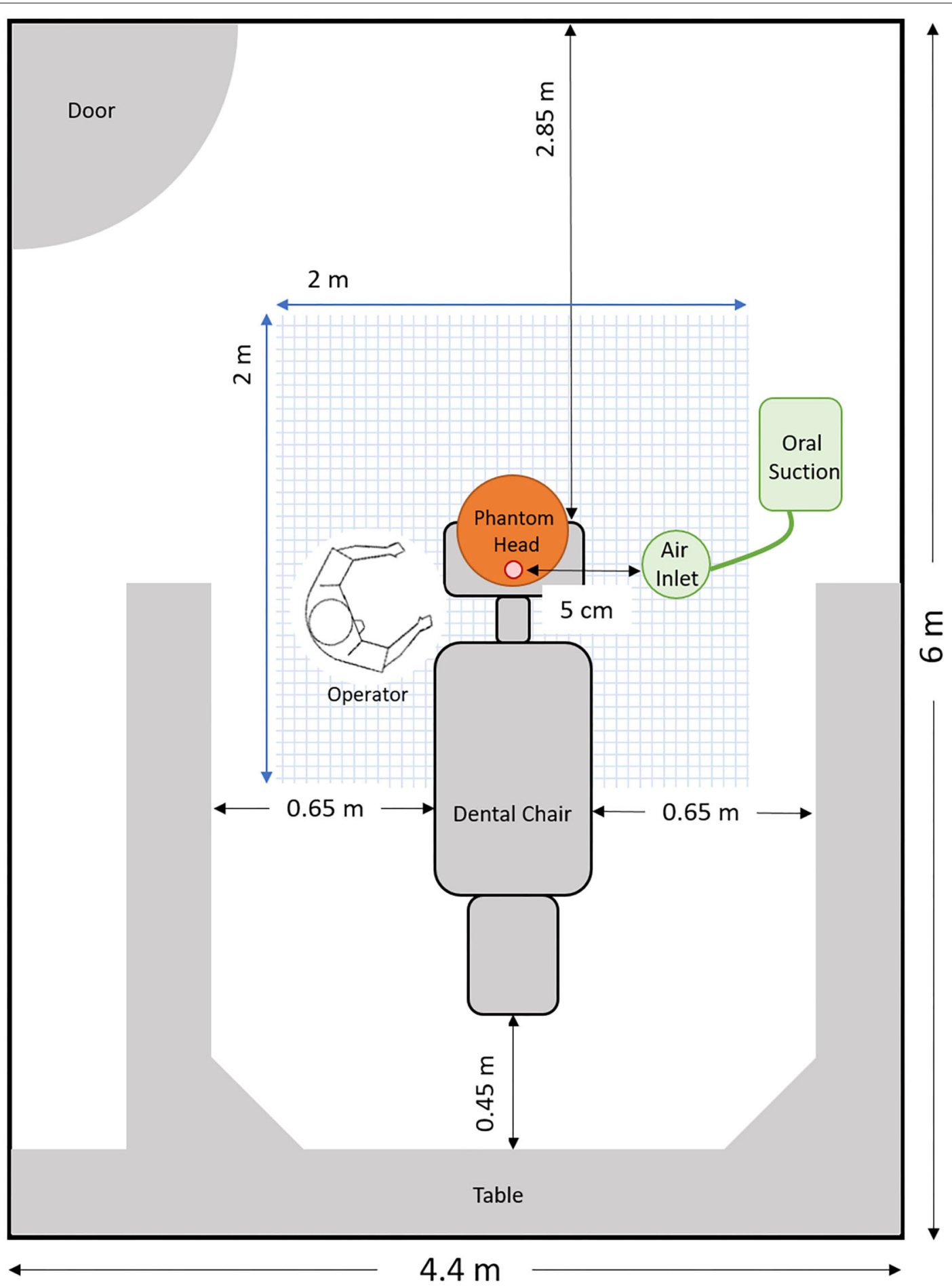

$=$ Papers covered on the floor

FIGURE 1 | Floor plan of the clinic with dental chair, operator position, and experimental setup. 
A

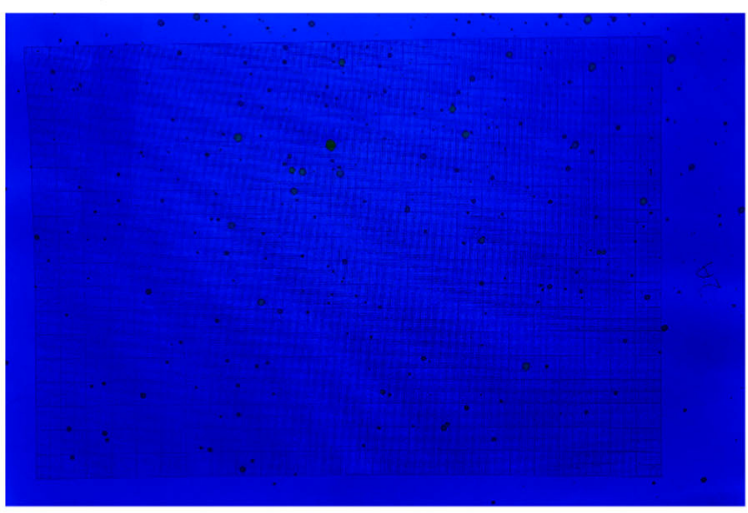

C

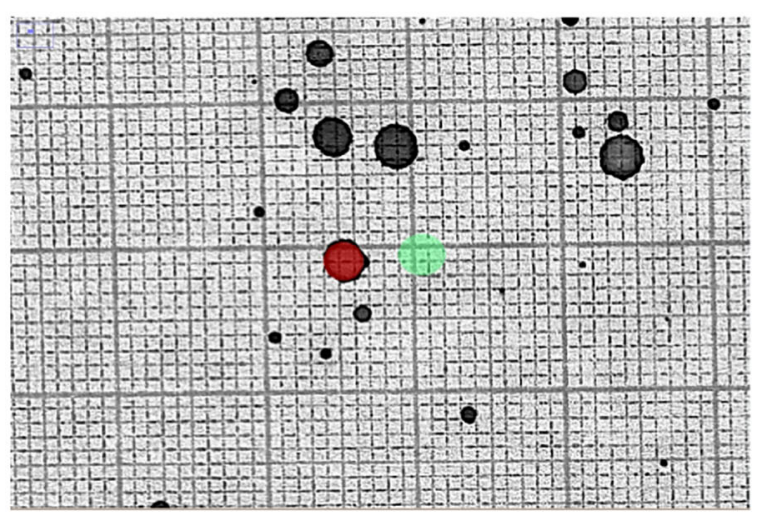

B

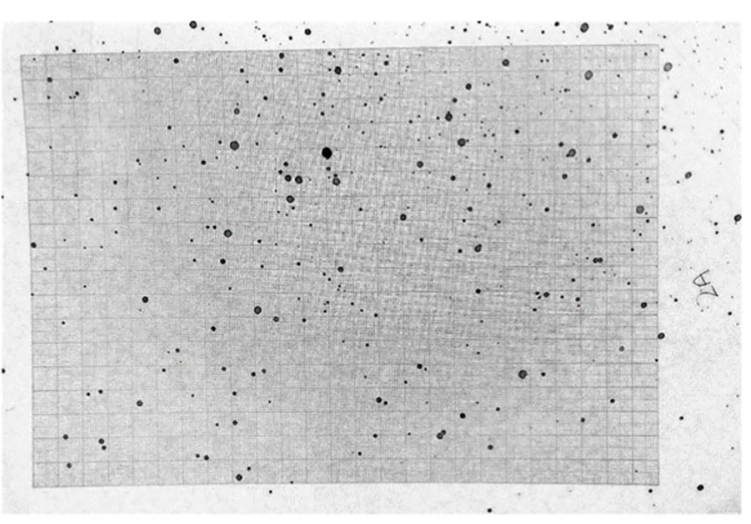

D

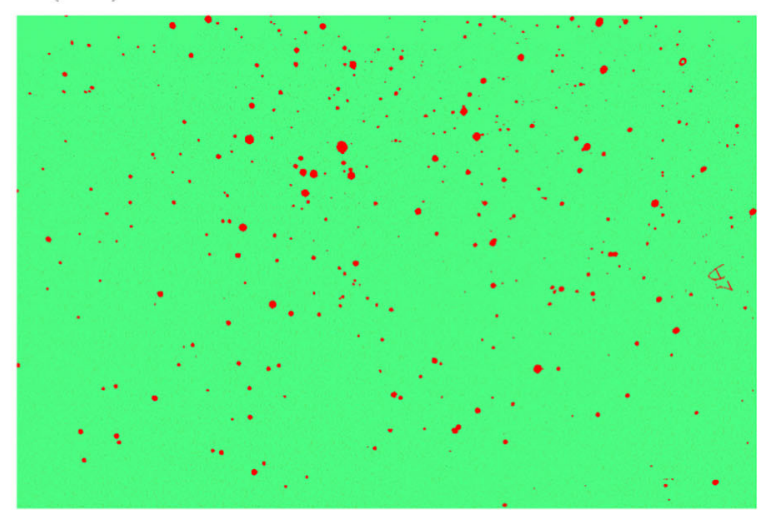

E

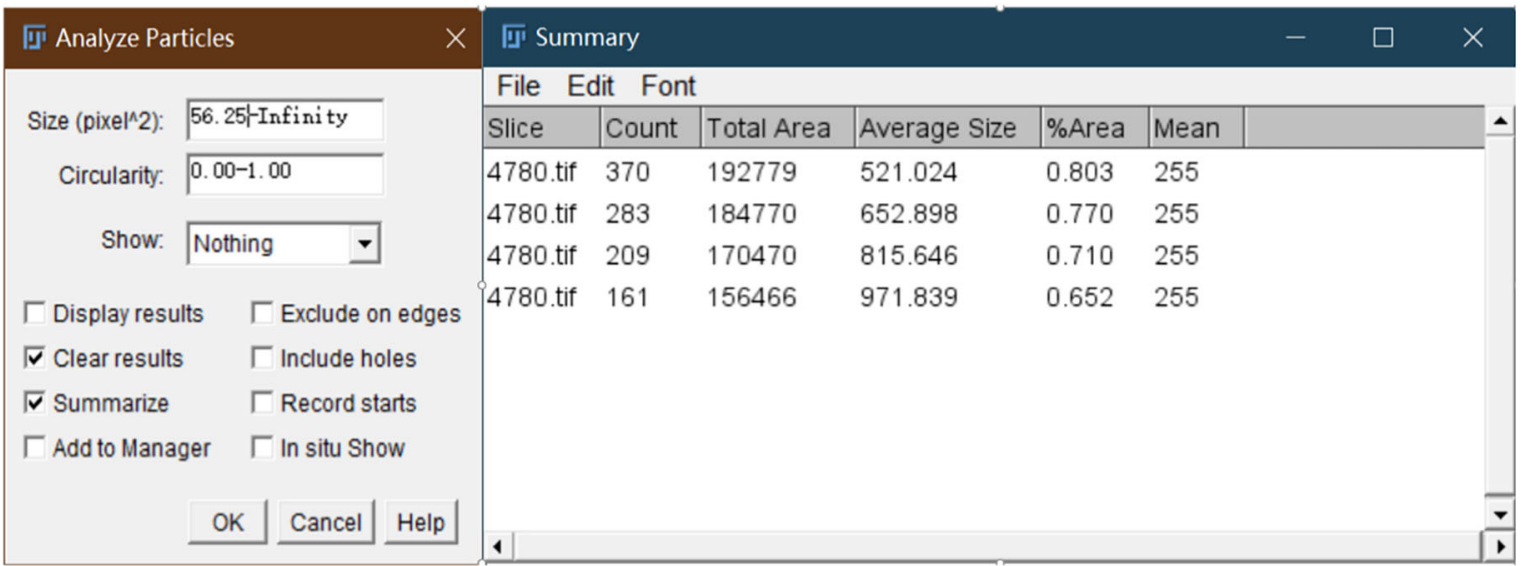

FIGURE 2 | (A) Photographs were taken to form an image for the processing of the machine learning algorithm software for droplet counting. (B) Backgrounds of the images were subtracted in a rolling ball radius of 50 pixels, and bright outliners (noise) of 2-pixel radius were removed. (C) To train the machine learning algorithm, one to two areas of aerosol drops (classified as class 1 in red) and background (classified as class 2 in green) were marked. (D) A classified image will then be created. (E) Count, total area, and average size of the droplets were determined with the software automatically. 
of the phantom head without any extra personnel. The same operating procedure was performed three times.

\section{Determination of Aerosols and Droplets}

A five-channel particle counter (3887D; Kanomax, Japan) was placed at the mouth opening of the phantom head. Aerosols with particle sizes of $0.3,0.5,1,3$, and $5 \mu \mathrm{m}$ were measured simultaneously before and during the above operation conditions $(\mathrm{a}-\mathrm{d})$.

For the measurement of droplets, a light-emitting device $(420-480 \mathrm{~nm})$ was used to glow the fluorescein in green color on the pieces of paper and environments to locate the droplets immediately after each round of drilling. A steel measuring tape ( $3 \mathrm{~m}$; Powerlock; Stanley, United States) was used to measure the farthest distance of the droplets from the point of vertical projection of the oral cavity of the phantom head on the floor in six directions. Photographs were then taken of the pieces of paper, and the sizes of droplet sizes the pieces of paper were determined with the aid of an open source image processing package with machine learning algorithm software (Trainable Weka Segmentation, Fiji). The images were resized and converted into 8 bits black and white format. The backgrounds of the images were then subtracted in rolling ball radius of 50 pixels, and bright outliners (noise) of 2-pixel radius were removed. After the contrast of the images were enhanced, the machine learning algorithm software was used to identify the droplets and background by manually marking one to two areas of aerosol drops on the pieces of paper. The program trained 500 areas before use. The total count function was used to find out the number of counts with respect to different sizes of droplets on pieces of paper (Figures 2A-E).

\section{Statistical Analysis}

One-way ANOVA with Tukey's honestly significant difference (HSD) post-hoc test was performed to analyze the difference in droplet distance for each group at 95\% confidence level (SPSS 22; IBM, NY, United States). A 5\% level of significance was applied.

\section{RESULTS}

Table 1 shows the mean particle counts per cubic feet for aerosol particles at baseline level and under different suction conditions. It is shown that the handpiece irrigation procedure without suction would increase particle counts. Low-volume suction reduced the particle counts of size $0.5-5 \mu \mathrm{m}$, but less effective than the groups with high-volume suction or external oral suction unit combined with low-volume suction. The combination of high- and low-volume suction was most effective in reducing aerosol of $0.3-1 \mu \mathrm{m}$, while the combination of external oral suction and low volume suction was most effective in reducing the aerosol count of 3-5 $\mu \mathrm{m}$. There was no statistical difference between the high-volume suction and external oral suction when combined with the low volume suction in all particle sizes of the aerosols.

Droplets were always found on dental clinic floors, face shields, operator gowns, and suction devices (Figure 3). Table 2 shows the distance of droplets using different suction systems. The different suction systems performed differently with statistical significance $(p=0.007)$ in terms of droplet distance (Table 3), whereas using (c) high volume suctions (41.1 \pm $22.9 \mathrm{~cm})$ and $(\mathrm{d})$ external oral suction unit $(39 \pm 18.2 \mathrm{~cm})$ had significantly reduced the spread of droplets when compared with (a) without suction $(58.9 \pm 17.1 \mathrm{~cm})$.

Figure 4 illustrates the droplet size distributions on the pieces of paper. Using the predetermined liquid absorbency of $0.2 \%$ fluorescein in normal saline on the pieces of paper used in the experiment according to gravimetric principle $\left(1.68 \mathrm{mg} / \mathrm{mm}^{3}\right)$, the estimated sizes of droplets generated by the handpiece drilling procedure were calculated. Accordingly, a $20-\mu \mathrm{m}$ droplet occupies a $\sim 0.25 \mathrm{~mm}^{2}$ stain area of the 80 -gsm pieces of paper. It is shown that there was a wide range of droplets that existed from $<20$ (stain area $0-0.25 \mathrm{~mm}^{2}$ ) to $>480 \mu \mathrm{m}$ (stain area $>$ $3 \mathrm{~mm}^{2}$ ) without suction or with low-volume suction only. In contrast, droplets with sizes $<40$ and $160-480 \mu$ m were unable to be found in the group with external oral suction and lowvolume suction, and all other ranges of droplet size were below

TABLE 1 | Mean (SD) particle counts per cubic feet for 0.3-5- $\mu \mathrm{m}$ aerosol particles under different suction systems.

\begin{tabular}{|c|c|c|c|c|c|c|c|}
\hline Particle size & $\begin{array}{c}\text { No operation } \\
\text { (background } \\
\text { count) }\end{array}$ & No suction & $\begin{array}{l}\text { Low volume } \\
\text { suction }\end{array}$ & $\begin{array}{c}\text { Low }+ \text { High } \\
\text { volume vacuum } \\
\text { suction }\end{array}$ & $\begin{array}{l}\text { Low }+ \\
\text { External oral } \\
\text { suction }\end{array}$ & $\begin{array}{c}\text { Without any } \\
\text { dental } \\
\text { procedure }\end{array}$ & $\begin{array}{l}P \text {-value (compare } \\
\text { different suctions } \\
\text { with no suction) }\end{array}$ \\
\hline $0.3 \mu \mathrm{m}$ & $\begin{array}{c}560,500 \\
(224,600)\end{array}$ & $\begin{array}{c}1,369,000^{b} \\
(229,800)\end{array}$ & $\begin{array}{c}1,550,000^{b} \\
(276,500)\end{array}$ & $\begin{array}{l}731,100^{a} \\
(121,100)\end{array}$ & $\begin{array}{c}1,059,000^{a, b} \\
(156,000)\end{array}$ & $\begin{array}{c}1,328,000^{b} \\
(11,520)\end{array}$ & 0.002 \\
\hline $0.5 \mu \mathrm{m}$ & $\begin{array}{c}70,200 \\
(43,870)\end{array}$ & $\begin{array}{r}623,400^{f} \\
(28,920)\end{array}$ & $\begin{array}{r}349,300^{e} \\
(49,800)\end{array}$ & $\begin{array}{c}118,600^{c} \\
(36,900)\end{array}$ & $\begin{array}{c}177,900^{\mathrm{C}} \\
(12,360)\end{array}$ & $\begin{array}{c}264,300^{d} \\
(5,000)\end{array}$ & $<0.001$ \\
\hline $1.0 \mu \mathrm{m}$ & $\begin{array}{c}4,240 \\
(4,000)\end{array}$ & $\begin{array}{l}479,000 \\
(22,300)\end{array}$ & $\begin{array}{l}81,240^{i} \\
(7,500)\end{array}$ & $\begin{array}{c}25,260^{9} \\
(5,750)\end{array}$ & $\begin{array}{c}38,280^{g, h} \\
(36,310)\end{array}$ & $\begin{array}{c}59,160^{h, i} \\
(1,500)\end{array}$ & $<0.001$ \\
\hline $3.0 \mu \mathrm{m}$ & $\begin{array}{l}1,560 \\
(160)\end{array}$ & $\begin{array}{l}300,000 \\
(18,900)\end{array}$ & $\begin{array}{c}2,760^{k} \\
(350)\end{array}$ & $\begin{array}{c}4,560^{k} \\
(880)\end{array}$ & $\begin{array}{l}2,280^{k} \\
(1,880)\end{array}$ & $\begin{array}{c}3,420^{k} \\
(300)\end{array}$ & $<0.001$ \\
\hline $5.0 \mu \mathrm{m}$ & $\begin{array}{c}620 \\
(140)\end{array}$ & $\begin{array}{l}191,900^{n} \\
(12,000)\end{array}$ & $\begin{array}{l}660^{\mathrm{m}} \\
(120)\end{array}$ & $\begin{array}{l}480^{\mathrm{m}} \\
(120)\end{array}$ & $\begin{array}{l}780^{\mathrm{m}} \\
(100)\end{array}$ & $\begin{array}{c}1,200^{\mathrm{m}} \\
(120)\end{array}$ & $<0.001$ \\
\hline
\end{tabular}

*Different superscript letters indicate significant differences $(p<0.05)$ compare with different suction settings. 


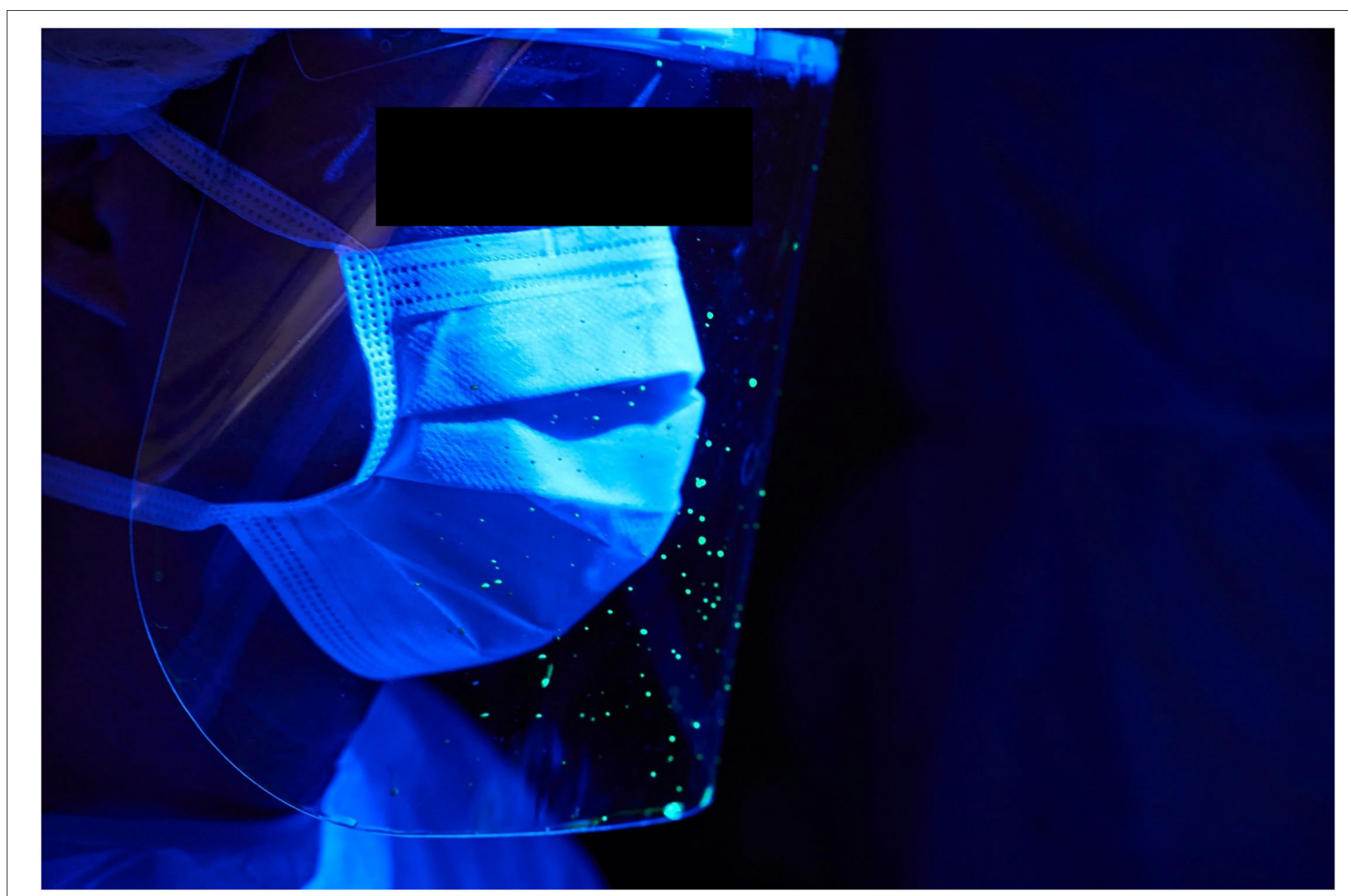

FIGURE 3 | Florescence droplets were found on dental clinic floors, face shields, operator gowns, and suction devices.

TABLE 2 | Distances of droplet spread using different suction systems.

\begin{tabular}{lccccc}
\hline Suction & $\boldsymbol{N}$ & Mean $^{(\mathbf{c m})^{*}}$ & SD & Minimum & Maximum \\
\hline No suction & 18 & $58.9^{\mathrm{A}}$ & 17.1 & 37.0 & 91.0 \\
Low volume suction & 18 & $55.1^{\mathrm{A}, \mathrm{B}}$ & 22.1 & 20.0 & 104.0 \\
Low + high volume suction & 18 & $41.1^{\mathrm{B}}$ & 22.9 & 13.0 & 86.0 \\
Low + external oral suction & 18 & $39.00^{\mathrm{B}}$ & 18.2 & 11.0 & 72.0 \\
\hline
\end{tabular}

${ }^{*}$ Different superscript letters indicate significant differences $(p<0.05)$.

TABLE 3 | One-way ANOVA table for the droplet analysis.

\begin{tabular}{lccccc}
\hline & Sum of squares & df & Mean square & $\boldsymbol{F}$ & Sig. \\
\hline Between groups & 5344.278 & 3 & 1781.426 & 4.368 & 0.007 \\
Within groups & 27733.667 & 68 & 407.848 & & \\
\hline Total & 33077.944 & 71 & & & \\
\hline
\end{tabular}

20 counts. For the group with high-volume vacuum suction and low volume suction, droplets $>120 \mu \mathrm{m}$ were reduced to singledigit counts, while keeping all ranges of droplets size within $<100$ counts.

\section{DISCUSSION}

The key findings of the study were: (1) the combinations of external oral suction + low volume suction and high-volume suction + low volume suction significantly reduced the distance of droplet spread; (2) all suction settings reduced the amount of aerosol; and (3) the external oral suction + low volume suction combination was best in reducing droplets, followed by the highvolume suction + low-volume suction combination. This study showed that the use of the external oral suction system or highvolume suction with low-volume surgical suction was effective in reducing aerosol and droplet contamination in the dental clinic environment. Apparently, the results revealed that the use of external oral suction systems could be useful for two-handed dentists to reduce aerosols in dental settings.

The COVID-19 pandemic has affected the whole world in all aspects. Measures, such as social distancing, partial or complete lockdowns, and closure of facilities to avoid gatherings, were implemented to reduce the spread of the severe acute respiratory syndrome coronavirus-2 (SARS-CoV-2) virus. Healthcare workers are considered to be at risk because of the frontline close contact with potential COVID-19-positive individuals. Dentists and oral and maxillofacial surgeons, in particular, are considered to be at a higher risk, because they 


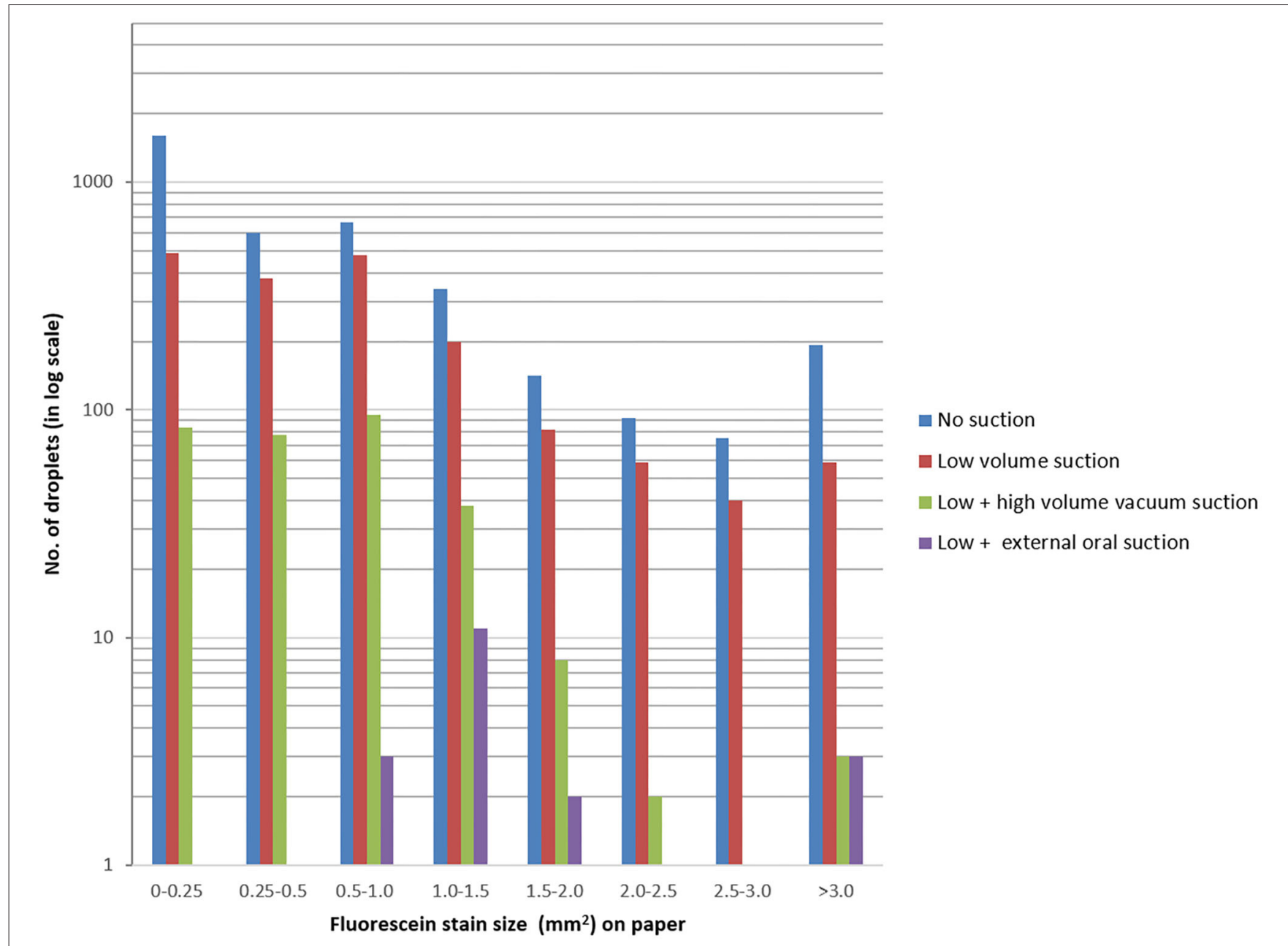

FIGURE 4 | Number of droplets vs. fluorescein stain size $\left(\mathrm{mm}^{2}\right)$ on pieces of paper. Note that a $20-\mu \mathrm{m}$ droplet would create a $0.25 \mathrm{~mm}{ }^{2-}$ stain on the paper.

are exposed to the oral cavity, which may carry high viral loads with continuous replication of virus particles in positive patients (13). In August 2020, WHO recommended to delay all routine non-urgent oral healthcare until the community transmission rate of COVID-19 was low (14). The recommendation also acknowledged the need for emergency treatment, especially for infection management, during the pandemic, which might unavoidably put dentists at risk if aerosol-/droplet-generating procedures are needed, especially in procedures where the rubber dam application is not possible. Impacted third molar is a common cause of dental infection emergencies. Surgical removal of the impacted third molar is usually performed with a motor rotary instrument connected to a self-irrigation system as set in this experiment, which generates aerosols and droplets. We conducted this study to demonstrate the effectiveness of different combinations of suction systems, and to find the best combination to recommend to the dental profession to reduce the amount and distance of spread of aerosols and droplets when these procedures are performed. The implication of this study was to improve safety in the dental practice and to seek a solution that can reduce the viral load in case an asymptomatic COVID19-positive patient is treated by these procedures. Nonetheless, it should be noted that this study is not intended to provide direct data on the spread of contamination, because the fluorescein tracing used in this experiment cannot be used for this aim.

Several studies proved that high-volume suction could significantly reduce aerosol contamination by more than $90 \%$ $(11,15)$. Jacks reported in a laboratory study that high-volume suction significantly reduced aerosol in ultrasonic scaling when compared with a standard low-volume saliva ejector (11). Harrel et al. also reported a similar finding, with 93\% reduction of contaminated square by the aerosol with high-volume suction in ultrasonic scaling when compared with a low-volume saliva ejector (15). Recently, Ravenel et al. (16) used a PM2.5 (2.5 micron) test device, and a fluorescein model confirmed that the use of high-volume suction was the key to reduce spatter and aerosols. Nagraj et al. (17) published in Cochrane Review about using high-volume suction might reduce bacterial contamination in short distance, but not in long distance clinically. Holloman et al. reported contradicting findings in a randomized clinical 
trial, and found similar colony-forming units of bacteria from the aerosol in both low- or high-volume suction groups (10). Ionescu et al. (18) also found that high-volume suction has no significant influence on viral contamination. It seems to be that the results are not consistent because of different test methodologies and clinical environments. Different sizes of dental aerosol particles behaved differently at various clinical settings (19). However, most studies on aerosols and spatters were using ultrasonic scaling models or high-speed air-driven rotary handpieces, and to the knowledge of the authors, there were no studies on electricdriven surgical motor handpieces. Our study demonstrated the effectiveness of aerosol and droplet reduction of different suction combinations on surgical motor handpieces, which added new information to the literature.

Studies have been using Coronavirus 229E associated with real-time PCR detection techniques (18) or with $\Phi 6$ bacteriophage (a surrogate virus for SARS-CoV-2) host Pseudomonas syringae with settle plate measurement to mimic clinical situaitons (20). These biological substances are commonly put in manikins or mixed with artificial saliva in phantom head to generate a biologically sound artificial mouth condition, and a dental handpiece is used to form bioaerosols under certain dental procedures. We recognize the importance of using such important mouth-mimicking models to illustrate the mixture of mouth liquids and lubricant from the instruments to generate the aerosol. Nonetheless, Meethil et al. (21) recently discovered that the majority of microbes were from irrigant fluids, which contributed $78 \%$ of microorganism in aerosols, and only $0.1-1.2 \%$ were contributed from human saliva. Apparently, Meethil et al. also identified that environmental contamination from instruments, e.g., implant handpieces, could be a surprising source of bioload in dental aerosol. While it could be debatable about the methodology using with microorganism or not, our current method mainly displayed both the aerosols and droplets in an easy visual way, such that the flow pattern of aerosols

\section{REFERENCES}

1. Leung NHL, Chu DKW, Shiu EYC, Chan KH, McDevitt JJ, Hau BJP, et al. Respiratory virus shedding in exhaled breath and efficacy of face masks. Nat Med. (2020) 26:676-80. doi: 10.1038/s41591-020-0843-2

2. van Doremalen N, Bushmaker T, Morris DH, Holbrook MG, Gamble A, Williamson BN, et al. Aerosol and surface stability of SARS-CoV2 as compared with SARS-CoV-1. N Engl J Med. (2020) 382:15647. doi: 10.1056/NEJMc2004973

3. Stadnytskyi V, Bax CE, Bax A, Anfinrud P. The airborne lifetime of small speech droplets and their potential importance in SARS-CoV-2 transmission. Proc Natl Acad Sci USA. (2020) 117:11875-7. doi: 10.1073/pnas.2006874117

4. World Health Organization. Transmission of SARS-CoV-2: Implications for Infection Prevention Precautions. (2020). Available online at: https:// www.who.int/publications/i/item/modes- of-transmission-of-virus-causingcovid-19-implications-for-ipc-precaution-recommendations (accessed June 01, 2021).

5. Zemouri C, de Soet H, Crielaard W, Laheij A. A scoping review on bioaerosols in healthcare and the dental environment. PLoS ONE. (2017) 12:e0178007. doi: 10.1371/journal.pone. 0178007

6. Madden RM, Hausler WJ Jr. Microbiological comparison of dental handpieces. 1. Preliminary report. J Dental Res. (1963). 42:1146-51. doi: 10.1177/00220345630420050801 and droplets at any clinical environment (urban, rural, natural ventilation, mechanical ventilation, hospital, private, etc.) can be easily illustrated at real time setting under blue ray florescence. Further studies are warranted to examine and illustrate in real time to investigate how these environmental parameters may affect the spread of the aerosol.

Extraoral suctions have become popular during the COVID19 pandemic. The stand-alone suction system contains a HEPA filter and ultra-violet light for disinfection, and serves to decontaminate aerosols, droplets, and air that are vacuumed into the system. It does not require an additional assistant to hold a high-volume suction next to the operating field, which saves manpower cost and reduces the chance of an additional exposure to potential viral particles near the operating field. Different brands have different performances in terms of suctioning efficiency, which was not our aim to compare in this study. A drawback of extra-oral suction is that the noise generated during its function could be a nuisance to patients and the dental team, and it could also affect the communication between the operator and the patient. However, it is proved in this study that it could improve safety in the dental clinic environment by effectively reducing aerosols and droplets in surgical procedures.

\section{DATA AVAILABILITY STATEMENT}

The raw data supporting the conclusions of this article will be made available by the authors, without undue reservation.

\section{AUTHOR CONTRIBUTIONS}

JT: analyzed the data and conceived, designed, and wrote the article. HD: acquired and analyzed the data. KH: acquired the data and drafted the article. YL: conceived, designed, critically revised, and wrote the article. All authors contributed to the article and approved the submitted version.

7. Davies A, Thompson KA, Giri K, Kafatos G, Walker J, Bennett A. Testing the efficacy of homemade masks: would they protect in an influenza pandemic? Disaster Med Public Health Prep. (2013) 7:413-8. doi: 10.1017/dmp.2013.43

8. Li DTS, Samaranayake LP, Leung YY, Neelakantan P. Facial protection in the era of COVID-19: a narrative review. Oral Dis. (2020). doi: 10.20944/preprints202005.0470.v1

9. American Dental Association. As Dental Practices Resume Operations, ADA Offers Continued Guidance. Recommendations Include Changes Before, During and After Appointments to Protect Patients and Dental Team. (2020). Available online at: https://www.ada.org/en/press-room/news-releases/2020archives/may/as-dental-practices-resume-operations-ada-offers-continuedguidance?utm_source $=$ cpsorg\&utm_medium $=$ cpsalertbar\&utm_content $=$ $\mathrm{cv}$-continuedguidance-statement\&utm_campaign=covid-19 (accessed June 01, 2021).

10. Holloman JL, Mauriello SM, Pimenta L, Arnold RR. Comparison of suction device with saliva ejector for aerosol and spatter reduction during ultrasonic scaling. J Am Dent Assoc. (2015) 146:27-33. doi: 10.1016/j.adaj.2014.10.001

11. Jacks ME. A laboratory comparison of evacuation devices on aerosol reduction. J Dent Hyg. (2002) 76:202-6.

12. Mousavi ES, Godri Pollitt KJ, Sherman J, Martinello RA. Performance analysis of portable HEPA filters and temporary plastic anterooms on the spread of surrogate coronavirus. Build Environ. (2020) 183:107186. doi: $10.1016 /$ j.buildenv.2020.107186 
13. Zou L, Ruan F, Huang M, Liang L, Huang H, Hong Z, et al. SARS-CoV-2 viral load in upper respiratory specimens of infected patients. N Engl J Med. (2020) 382:1177-9. doi: 10.1056/NEJMc2001737

14. Organization WH. Considerations for the Provision of Essential Oral Health Services in the Context of COVID-19. World Health Organization (2020). Available online at: WHO/2019-nCoV/Oral_health/2020.1

15. Harrel SK, Barnes JB, Rivera-Hidalgo F. Reduction of aerosols produced by ultrasonic scalers. J Periodontol. (1996) 67:2832. doi: 10.1902/jop.1996.67.1.28

16. Ravenel TD, Kessler R, Comisi JC, Kelly A, Renne WG, Teich ST. Evaluation of the spatter-reduction effectiveness and aerosol containment of eight dry-field isolation techniques. Quintessence Int. (2020) 51:660-70. doi: 10.3290/j.qi.a44919

17. Kumbargere Nagraj S, Eachempati P, Paisi M, Nasser M, Sivaramakrishnan G, Verbeek JH. Interventions to reduce contaminated aerosols produced during dental procedures for preventing infectious diseases. Cochrane Database Syst Rev. (2020) 10:CD013686. doi: 10.1002/14651858.CD013686.pub2

18. Ionescu AC, Brambilla E, Manzoli L, Orsini G, Gentili V, Rizzo R. Efficacy of personal protective equipment against coronavirus transmission via dental handpieces. J Am Dent Assoc. (2021) 152:631-40. doi: 10.1016/j.adaj.2021.03.007

19. Graziani F, Izzetti R, Lardani L, Totaro M, Baggiani A. Experimental evaluation of aerosol production after dental ultrasonic instrumentation: an analysis on fine particulate matter perturbation. Int J Environ Res Public Health. (2021) 18:3357. doi: 10.3390/ijerph18073357
20. Vernon JJ, Black EVI, Dennis T, Devine DA, Fletcher L, Wood DJ, et al. Dental mitigation strategies to reduce aerosolization of SARS-CoV-2. J Dent Res. (2021). doi: 10.1101/2021.03.24.21254254. [Epub ahead of print].

21. Meethil AP, Saraswat S, Chaudhary PP, Dabdoub SM, Kumar PS. Sources of SARS-CoV-2 and other microorganisms in dental aerosols. J Dental Res. (2021) 100:817-23. doi: 10.1177/00220345211015948

Conflict of Interest: The authors declare that the research was conducted in the absence of any commercial or financial relationships that could be construed as a potential conflict of interest.

Publisher's Note: All claims expressed in this article are solely those of the authors and do not necessarily represent those of their affiliated organizations, or those of the publisher, the editors and the reviewers. Any product that may be evaluated in this article, or claim that may be made by its manufacturer, is not guaranteed or endorsed by the publisher.

Copyright (c) 2021 Tsoi, Ding, Hon and Leung. This is an open-access article distributed under the terms of the Creative Commons Attribution License (CC BY). The use, distribution or reproduction in other forums is permitted, provided the original author(s) and the copyright owner(s) are credited and that the original publication in this journal is cited, in accordance with accepted academic practice. No use, distribution or reproduction is permitted which does not comply with these terms. 